\title{
Validity of a short food frequency questionnaire for estimating nutrient intake in elderly people
}

\author{
BY C. C. HORWATH \\ Department of Human Nutrition, University of Otago, PO Box 56, Dunedin, New Zealand
}

(Received 10 February 1992 - Accepted 7 September 1992)

\begin{abstract}
Nutrient intakes estimated using a short self-administered semi-quantitative food frequency questionnaire (FFQ) were compared with results obtained from five $2 \mathrm{~d}$ diet records using household measures in a group of fifty-three elderly people (mean age 70 years) in Dunedin, New Zealand in 1989. Mean intakes for most nutrients were less than $5 \%$ different between the two methods. Correlations between the nutrient intake values (excluding supplements) from the diet records and those from the FFQ ranged from 0.34 for $\mathrm{Zn}$ in women to more than $\mathbf{0 . 7 5}$ for protein, $\mathrm{Zn}$ and $\mathrm{Ca}$ in men. For most nutrients, at least $70 \%$ of the subjects when classified by the food records fell into the same quintile or into the within-onequintile category when classified by the FFQ. These data indicate that in elderly subjects a simple selfadministered semi-quantitative FFQ can provide very similar information (for both group and individual intakes for many nutrients) to that obtained from $10 \mathrm{~d}$ of careful diet recording.
\end{abstract}

Food frequency questionnaire: Elderly: Nutrition surveys: Epidemiologic methods

The estimation of nutrient intake is often a difficult task, but can present extra challenges in elderly people. Declining short-term memory can mean that the $24 \mathrm{~h}$ recall method may be particularly inappropriate, and several investigators have demonstrated that dietary recall ability decreases with age (Trulson \& McCann, 1959; Campbell \& Dodds, 1967). The very elderly or very frail can become easily fatigued and frustrated with long diet history interviews or excessively long questionnaires, and may take far longer than younger persons to complete them, being particularly prone to digressions in interview situations (Kelsey et al. 1989). The diet record method demands a high degree of cooperation and motivation from subjects of all ages. In contrast, the food frequency questionnaire (FFQ) method involves a comparatively low burden to respondents, and by requesting information on their usual diet, does not rely on short-term memory. On the other hand, this method does require some fairly complex summing and averaging operations in order to arrive at a single frequency of consumption estimate, and it is unknown whether or to what extent these abilities decline with age.

Studies assessing the performance of FFQ in comparison with multiple diet records suggest that this method can reliably place individuals into broad categories of nutrient intake (Willett et al. 1985; Block et al. 1986; Pietinen et al. 1988a, b). Response rates of nearly $80 \%$ have been achieved with random population samples of elderly people and mail-administered FFQ (Baghurst \& Record, 1983, 1987; Horwath, 1989). A short FFQ has been validated in elderly people as a measure of food use patterns by comparison with a direct observation of domestic food stores (Horwath \& Worsley, 1990). The kappa statistic indicated good agreement (in all cases greater than that expected due to chance) between the reported use of individual foods in the FFQ and the observed presence or absence of those foods in the subject's home. In addition, the diet record method has been 
used to validate a FFQ specifically designed to assess only Ca intake in elderly subjects (Nelson et al. 1988). However, tests of the validity of general FFQ designed to estimate a range of nutrient intakes have rarely been conducted in elderly populations.

The findings presented here are the results of a study designed to evaluate the validity of a short semi-quantitative FFQ as a measure of nutrient intake in a group of elderly volunteers. The comparison method chosen was multiple days of diet recording using household measures.

\section{METHODS}

Study design

Subjects were recruited from a group of elderly people who had previously attended health seminars conducted by the Medical Research Foundation in Dunedin, New Zealand. All were apparently healthy, independently-living Caucasian individuals. Fifty-five subjects were approached, all agreed to take part and fifty-three completed the study (twenty-four men and twenty-nine women aged between 54 and 86 years). All subjects were visited at home by the investigator for recruitment, and then instructed about the details of the study. Each subject was required to complete five $2 \mathrm{~d}$ diet records spread out evenly over a period of 2 months, and a self-administered semi-quantitative FFQ. Details of these two methods of dietary assessment are described on pp. 4-6. In order to cancel any potential training effects, subjects were randomly assigned to one of two groups, one which completed the FFQ first, and the other which completed the diet record first. The FFQ was completed either 2 weeks before or 2 weeks after the completion of the diet records. Both records and FFQ were collected by the investigator to provide an opportunity for review.

\section{The semi-quantitative $F F Q$}

The FFQ included a list of some 120 food and drink items plus qualitative questions concerning food preparation and cooking practices (particularly those affecting the fat or salt content of foods). The purpose of the FFQ was to assess usual food consumption over the previous year. However, for those foods whose consumption tends to be highly seasonal (e.g. certain fruits and vegetables), the questionnaire took into account seasonality by asking specifically about the frequency of intake of these items when they were in season. Subjects were instructed to indicate their usual frequency of intake when the particular items were in plentiful supply. The consumption of items out of season (e.g. fresh stone fruit or berries) was assumed to be negligible. The time and duration of the plentiful season varies from one item to another, and New Zealand tables were available which documented for each fruit and vegetable the months of the year when the supply is plentiful. The subjects' reported frequency of consumption for each of the seasonal fruits and vegetables was assumed to occur only in these months of the year. This approach was adopted as it seemed preferable to expecting respondents to attempt the complex and difficult task of averaging their intake of highly seasonal foods over the year, and because pretesting showed that the majority of older adults rarely bought fruits and vegetables when these were out of season and thus expensive.

Selection of the food items was based on an earlier diet survey identifying those foods or food groups making important contributions to the diets of elderly New Zealand people (Birkbeck, 1983). A balance was necessary between adequate coverage of foods eaten by participants and minimal respondent burden. Much attention was devoted to the clarity of instructions and the nature of response scales, and the print used was larger than that in written questionnaires for the general population. In order to minimize fatigue and boredom, blocks of questions on the frequency of consumption of foods were interspersed with more qualitative questions on the types of foods eaten, on cooking methods or 
supplement use. The final design was the result of intensive pilot testing of various formats with more than 150 elderly people.

In response to the question 'How often do you usually eat these foods?', subjects were asked to choose from five options: 'never or rarely', 'about monthly', 'once or twice a week', 'three or four times a week' and 'about daily'. Slightly different categories were found during piloting to be more appropriate for most of the meat, fish and poultry items: 'never or rarely', 'about fortnightly', 'once a week', 'twice a week' and 'three or four times a week'. This is because people were generally able to be more specific about the frequency of consumption of these foods.

For those foods that are consumed by many people more than once daily, or for other foods for which quantification is both straightforward and very important, amounts per $\mathrm{d}$, per week or per month were requested in an open-ended format (e.g. number of eggs, biscuits or slices of bread; number of teaspoons of sugar in tea and coffee; number of glasses of milk, fruit juice, soft drinks, alcohol). For most foods the questionnaire sought only information on the usual frequency of intake. Inclusion of questions on serving size for each food was found to be impractical for the elderly due to greatly increased time required for completion. In any case, the accuracy with which people can, without the aid of measuring devices, describe amounts of food eaten in quantifiable terms is poor (Guthrie, 1984; Rapp et al. 1986). Furthermore, some evidence suggests that a dietary questionnaire limited to the determination of frequency of consumption can provide information on subjects' relative intake of specific nutrients (Samet et al. 1984; Pietinen et al. 1988 b). Estimation of nutrient intake from this questionnaire thus involved use of standard serving sizes for many foods. These were compiled from data on elderly people from previous New Zealand and Australian $24 \mathrm{~h}$ diet recall surveys (Baghurst \& Record, 1984; Wilson et al. 1990 and unpublished $24 \mathrm{~h}$ recall results from the Life in New Zealand survey). The standard portion sizes were the average amounts consumed by subjects in these surveys, and many of these were higher for men than women.

Subjects were personally instructed as to how to complete the questionnaire and were also given written instructions. Questionnaires were completed at home in the subjects' own time and took $30-40 \mathrm{~min}$ on average. For the majority of questions which were in the multiple-choice format, individuals were simply required to circle the answer most closely corresponding to their usual frequency of consumption or method of food preparation or cooking; writing was required only for those open-ended questions referring to amounts eaten. However, room was provided to enable subjects to describe their food habits if they felt these were not adequately described by the closed questions. The questionnaire was reviewed with the subject by the investigator, and any unanswered questions or unclear answers were completed and clarified.

\section{The reference method}

Multiple diet recording was chosen as the reference method, since it is generally considered the optimal method of dietary assessment when the aim is to measure usual nutrient intake for individuals, provided the number of days is high and the time period covered is long enough. For most nutrients, with the exceptions of retinol, carotene, $\mathrm{Cu}$, vitamin $\mathrm{B}_{12}$, polyunsaturated fat and cholesterol (Marr \& Heady, 1986; Nelson et al. 1989) $10 \mathrm{~d}$ should be sufficient to assess the usual intake. In this study, the total of $10 \mathrm{~d}$ of recording included three weekend days and at least one of each other day of the week. The maximum of two consecutive days for the recording periods was aimed at reducing boredom, fatigue and omissions and, thus, increasing the accuracy of record keeping. Careful instruction was given in the subjects' home regarding methods for recording amount of food and drinks (mainly using household measures) and on the need to record all additions to foods (e.g. 
Table 1. Characteristics of elderly subjects in Dunedin, New Zealand, 1989

\begin{tabular}{|c|c|c|c|c|c|c|}
\hline & \multirow[b]{2}{*}{$\begin{array}{l}\text { Mean } \\
\text { age }\end{array}$} & \multirow[b]{2}{*}{$\begin{array}{l}\text { Age } \\
\text { range }\end{array}$} & \multirow[b]{2}{*}{$\begin{array}{c}\text { Special } \\
\text { diet }(\%)\end{array}$} & \multicolumn{3}{|c|}{ Supplement use } \\
\hline & & & & $\begin{array}{c}\text { Regular } \\
\text { user* }(\%)\end{array}$ & $\begin{array}{l}\text { Irregular } \\
\text { user }(\%)\end{array}$ & $\begin{array}{c}\text { Non-user } \\
(\%)\end{array}$ \\
\hline Men $(n$ 24) & 70 & $60-86$ & 21 & 29 & 8 & 71 \\
\hline Women (n 29) & 70 & $54-84$ & 24 & 45 & 10 & 52 \\
\hline
\end{tabular}

* Using supplements at least once weekly throughout the year. Some regular users also reported that there were other supplements which they used only on an occasional basis (e.g. ascorbic acid for colds) and, thus, they were also included in the irregular use category.

fats, sugars, sauces) and cooking methods. If it was difficult to describe amounts consumed in terms of household measures, the use of photographs of small, medium and large portions of several commonly-eaten foods was also possible (roast meat, chicken, casserole, blocks of cheese, cake, spaghetti, quiche or pie, pudding, muesli, vegetables (i.e. cauliflower, carrots and potato) and spreads of jam or marmite on bread). Emphasis was placed on the need to record all items at the time of eating and not from memory at the end of the day. The potential for subjects to modify their eating behaviour as a result of the recording process presents the main limitation of this method.

\section{Statistical analysis}

Nutrient values were computed using as the database the New Zealand food consumption tables which consist mainly of British and New Zealand data (Milligan et al. 1991). The database is continually being updated and expanded but at the time of this analysis included about 1000 food items. The FFQ results were analysed using a program specially developed in the Department of Human Nutrition. The program uses answers to questions concerning cooking and food preparation practices which affect fat content to adjust the values obtained from the main frequency questions. As the amounts of foods consumed vary from subject to subject, the use of standard portion sizes for many food items means that the figures resulting from the nutrient analysis program for individuals are likely to involve a large degree of error.

Means, standard deviations and ranges were calculated for nutrient intakes measured by diet records and questionnaires. Pearson correlations were also used to compare individual intakes between the two methods. Since most nutrient intakes were skewed toward higher values, $\log _{\mathrm{e}}$-transformed variables were used. Since the capacity of a questionnaire to classify or rank individuals by levels of nutrient intake is usually more important than the ability to measure group means (Block, 1982), both questionnaire and diet record nutrient results were divided into quintiles in order to examine their cross-classification. Cut-off points for quintiles were determined separately for diet records and for questionnaires. The percentage correctly classified in the extreme quintiles and the overall percentage correctly classified within one quintile were calculated. Due to chance alone, $52 \%$ of subjects would be expected to be correctly classified to within one quintile. Although the kappa statistic can be used to correct for chance agreement, its application is not advisable for grouped continuous data (Maclure \& Willett, 1987) as is the case in this study.

\section{RESULTS}

Table 1 details age, sex, supplement use, and the use of special diets among the fifty-three elderly people studied. Although the FFQ method is aimed primarily at ranking subjects 
Table 2. Mean daily intakes of energy and major nutrients estimated from $10 \mathrm{~d}$ diet records and food frequency questionnaires (FFQ)* in fifty-three elderly volunteers in Dunedin, New Zealand, 1989

\begin{tabular}{|c|c|c|c|c|c|c|c|}
\hline \multirow[b]{2}{*}{ Daily intake } & \multirow[b]{2}{*}{ Method } & \multicolumn{3}{|c|}{ Men ( $n$ 24) } & \multicolumn{3}{|c|}{ Women (n 29) } \\
\hline & & Mean & SD & Range & Mean & SD & Range \\
\hline \multirow[t]{2}{*}{ Energy $(\mathrm{MJ})$} & $10 \mathrm{~d}$ record & $8 \cdot 66$ & 1.88 & $3.85-11.08$ & $7 \cdot 16$ & $1 \cdot 20$ & $4 \cdot 95-9 \cdot 42$ \\
\hline & FFQ & $8 \cdot 56$ & 1.90 & $4 \cdot 78-12 \cdot 96$ & $7 \cdot 35$ & 1.48 & $4 \cdot 43-11 \cdot 13$ \\
\hline \multirow[t]{2}{*}{ Protein $(\mathrm{g})$} & $10 \mathrm{~d}$ record & 76 & 17 & $41-106$ & 68 & 9 & $46-86$ \\
\hline & FFQ & 72 & 18 & $34-110$ & 62 & 15 & $36-84$ \\
\hline \multirow[t]{2}{*}{ Carbohydrate (g) } & $10 \mathrm{~d}$ record & 262 & 59 & $107-374$ & 224 & 49 & $125-318$ \\
\hline & FFQ & 271 & 65 & $141-444$ & 245 & 52 & $145-364$ \\
\hline \multirow[t]{2}{*}{ Starch $(\mathrm{g})$} & $10 \mathrm{~d}$ record & 144 & 40 & $64-217$ & 117 & 27 & $56-176$ \\
\hline & FFQ & 112 & 26 & $51-177$ & 100 & 22 & $52-152$ \\
\hline \multirow[t]{2}{*}{ Total available sugars (g) } & $10 \mathrm{~d}$ record & 118 & 37 & $42-214$ & 105 & 36 & $31-191$ \\
\hline & FFQ & 159 & 46 & $67-267$ & 145 & 38 & $69-218$ \\
\hline \multirow[t]{2}{*}{ Total fat $(\mathrm{g})$} & $10 \mathrm{~d}$ record & 82 & 21 & $31-118$ & 65 & 15 & $32-90$ \\
\hline & FFQ & 78 & 21 & $42-115$ & 63 & 17 & $26-108$ \\
\hline \multirow[t]{2}{*}{ Saturated fatty acids (g) } & $10 \mathrm{~d}$ record & 36 & 11 & $10-57$ & 26 & 8 & $10-45$ \\
\hline & FFQ & 36 & 11 & $15-61$ & 26 & 10 & $11-51$ \\
\hline \multirow[t]{2}{*}{ Polyunsaturated fatty acids (g) } & $10 \mathrm{~d}$ record & 10 & 3 & $4-16$ & 9 & 3 & $5-16$ \\
\hline & FFQ & 9 & 4 & $3-18$ & 10 & 4 & $4-20$ \\
\hline \multirow[t]{2}{*}{ Monounsaturated fatty acids (g) } & $10 \mathrm{~d}$ record & 26 & 7 & $10-40$ & 21 & 5 & $9-30$ \\
\hline & FFQ & 25 & 7 & $13-38$ & 20 & 6 & $8-35$ \\
\hline \multirow[t]{2}{*}{ Cholesterol (mg) } & $10 \mathrm{~d}$ record & 312 & 108 & $168-538$ & 237 & 72 & $104-357$ \\
\hline & FFQ & 300 & 96 & $159-579$ & 216 & 69 & $79-324$ \\
\hline \multirow[t]{2}{*}{ Alcohol $(\mathrm{g}) \dagger$} & $10 \mathrm{~d}$ record & 6 & 8 & $0-27$ & 2 & 4 & $0-19$ \\
\hline & FFQ & 6 & 6 & $0-18$ & 2 & 4 & $0-17$ \\
\hline \multirow[t]{2}{*}{ Fibre (g) } & $10 \mathrm{~d}$ record & 25 & 7 & $14-44$ & 22 & 6 & $13-40$ \\
\hline & FFQ & 25 & 7 & $15-40$ & 25 & 7 & $13-40$ \\
\hline \multicolumn{8}{|l|}{$\%$ Energy as: } \\
\hline Protein & & $15 \ddagger$ & & $14 \S$ & $16 t$ & & $14 \S$ \\
\hline Fat & & $35^{+}$ & & 34 & 34 & & 32 \\
\hline Saturated fat & & 15 & & 16 & 13 & & 13 \\
\hline Polyunsaturated fat & & 4 & & 4 & 5 & & 5 \\
\hline Total carbohydrate & & 48 & & 51 & 50 & & 53 \\
\hline Starch & & 27 & & 21 & 26 & & 22 \\
\hline Sugars & & 22 & & 30 & 23 & & 32 \\
\hline Alcohol & & 2 & & 2 & 1 & & 1 \\
\hline
\end{tabular}

* For details of procedures, see pp. 4-6.

$\dagger$ The average daily alcohol intake is presented here only for comparison with other surveys.

$\$$ Values in this column were estimated by $10 \mathrm{~d}$ diet records.

$\S$ Values in this column were estimated by the FFQ.

according to their nutrient intake values, the absolute mean nutrient intake levels produced are also of interest and compare favourably with those based on the food records (Tables 2 and 3). Overall, most mean nutrient intakes estimated by the FFQ were within $5 \%$ of the mean food record values. Several others were approximately $90-110 \%$ of the intake levels based on food records. The greatest deviations from the record results were: the underestimation of starch and vitamin $\mathrm{B}_{12}$ by $15-20 \%$, the overestimation of ascorbic acid (women only) and sugars by about $35 \%$, and the overestimation of fibre (women only) and $\mathrm{Ca}$ by about $15 \%$. The questionnaire compared with the record tended to underestimate slightly the mean percent of energy derived from protein and fat, and to overestimate the mean percent derived from carbohydrate. Nutrient intake distributions and ranges were 
Table 3. Mean daily intakes (excluding supplements) of vitamins and minerals estimated from $10 \mathrm{~d}$ diet records and food frequency questionnaires $(F F Q) *$ in fifty-three elderly volunteers in Dunedin, New Zealand, 1989

\begin{tabular}{|c|c|c|c|c|c|c|c|}
\hline \multirow[b]{2}{*}{ Daily intake } & \multirow[b]{2}{*}{ Method } & \multicolumn{3}{|c|}{ Men $(n 24)$} & \multicolumn{3}{|c|}{ Women $(n 29)$} \\
\hline & & Mean & SD & Range & Mean & SD & Range \\
\hline \multirow[t]{2}{*}{ Retinol $(\mu \mathrm{g})$} & $10 \mathrm{~d}$ record & 1672 & 1441 & $540-5831$ & 1448 & 1339 & $492-7138$ \\
\hline & FFQ & 1652 & 467 & $477-2686$ & 1616 & 583 & $689-3122$ \\
\hline \multirow[t]{2}{*}{ Thiamin (mg) } & $10 \mathrm{~d}$ record & 1.42 & 0.47 & $0 \cdot 70-2 \cdot 38$ & $1 \cdot 19$ & $0 \cdot 37$ & $0.79-2.55$ \\
\hline & FFQ & $1 \cdot 30$ & 0.44 & $0 \cdot 65-2 \cdot 19$ & $1 \cdot 15$ & $0 \cdot 28$ & $0 \cdot 70-1.79$ \\
\hline \multirow[t]{2}{*}{ Riboflavin (mg) } & $10 \mathrm{~d}$ record & 1.90 & $0 \cdot 80$ & $0 \cdot 99-3 \cdot 80$ & 1.61 & 0.61 & $0.85-3.09$ \\
\hline & FFQ & 1.98 & 0.71 & $0.95-3.41$ & $1 \cdot 73$ & 0.52 & $0 \cdot 90-2.64$ \\
\hline \multirow[t]{2}{*}{ Nicotinic acid (mg) } & $10 \mathrm{~d}$ record & $34 \cdot 6$ & $10 \cdot 6$ & $16 \cdot 1-65 \cdot 9$ & $30 \cdot 4$ & $6 \cdot 4$ & $20-5-52 \cdot 9$ \\
\hline & FFQ & 31.9 & $7 \cdot 7$ & $17 \cdot 0-78 \cdot 1$ & $28 \cdot 7$ & $7 \cdot 3$ & $15 \cdot 3-42 \cdot 4$ \\
\hline \multirow[t]{2}{*}{ Pyridoxine (mg) } & $10 \mathrm{~d}$ record & 1.62 & 0.56 & $0.95-3.49$ & 1.41 & $0 \cdot 36$ & $0 \cdot 90-2 \cdot 22$ \\
\hline & FFQ & $1 \cdot 50$ & 0.46 & $0 \cdot 60-2 \cdot 28$ & $1 \cdot 36$ & 0.39 & $0.77-2 \cdot 11$ \\
\hline \multirow[t]{2}{*}{ Vitamin $\mathrm{B}_{12}(\mu \mathrm{g})$} & $10 \mathrm{~d}$ record & 6.57 & $7 \cdot 19$ & $1 \cdot 50-31 \cdot 77$ & $5 \cdot 19$ & 5.85 & $1 \cdot 60-34 \cdot 38$ \\
\hline & FFQ & $5 \cdot 30$ & $2 \cdot 81$ & $1 \cdot 93-11 \cdot 43$ & $4 \cdot 60$ & $2 \cdot 71$ & $0 \cdot 64-11 \cdot 19$ \\
\hline \multirow[t]{2}{*}{ Ascorbic acid (mg) } & $10 \mathrm{~d}$ record & 96 & 57 & $34-286$ & 111 & 42 & $53-225$ \\
\hline & FFQ & 105 & 53 & $40-257$ & 146 & 75 & $48-365$ \\
\hline \multirow[t]{2}{*}{ Total folate $(\mu \mathrm{g})$} & $10 \mathrm{~d}$ record & 233 & 74 & $126-406$ & 220 & 53 & $137-325$ \\
\hline & FFQ & 243 & 70 & $135-417$ & 236 & 62 & $111-358$ \\
\hline \multirow[t]{2}{*}{$\mathrm{Ca}(\mathrm{mg})$} & $10 \mathrm{~d}$ record & 810 & 333 & $402-1665$ & 724 & 242 & $366-1414$ \\
\hline & FFQ & 924 & 315 & $307-1507$ & 845 & 258 & $382-1262$ \\
\hline \multirow[t]{2}{*}{$\mathrm{Fe}(\mathrm{mg})$} & $10 \mathrm{~d}$ record & $12 \cdot 3$ & 2.6 & $6 \cdot 1-16 \cdot 4$ & $10-8$ & 1.8 & $8 \cdot 3-14 \cdot 7$ \\
\hline & FFQ & $11 \cdot 6$ & 2.5 & $5 \cdot 0-17 \cdot 5$ & $10^{-4}$ & $2 \cdot 3$ & $6 \cdot 6-15 \cdot 4$ \\
\hline \multirow[t]{2}{*}{$\mathrm{K}(\mathrm{mg})$} & $10 \mathrm{~d}$ record & 3443 & 911 & $1718-4963$ & 3061 & 528 & $2277-4025$ \\
\hline & FFQ & 3378 & 758 & $2110-4758$ & 3242 & 696 & $2173-4620$ \\
\hline \multirow[t]{2}{*}{$\mathrm{Cu}(\mathrm{mg})$} & $10 \mathrm{~d}$ record & 1.73 & 0.60 & $0.73-3.67$ & $1 \cdot 41$ & $0 \cdot 38$ & $0.94-2.63$ \\
\hline & $\mathrm{FFQ}$ & 1.47 & $0 \cdot 32$ & $0 \cdot 79-2 \cdot 11$ & $1 \cdot 39$ & 0.33 & $0 \cdot 92-2 \cdot 13$ \\
\hline \multirow[t]{2}{*}{$\mathrm{Zn}(\mathrm{mg})$} & $10 \mathrm{~d}$ record & $11 \cdot 0$ & $3 \cdot 0$ & $5 \cdot 1-18 \cdot 4$ & $9 \cdot 5$ & $2 \cdot 1$ & $6 \cdot 1-18 \cdot 1$ \\
\hline & FFQ & 9.9 & $2 \cdot 6$ & $4 \cdot 7-15 \cdot 0$ & $8 \cdot 6$ & $2 \cdot 1$ & $4 \cdot 5-12 \cdot 1$ \\
\hline \multirow[t]{2}{*}{ Se $(\mu \mathrm{g})$} & $10 \mathrm{~d}$ record & $39 \cdot 3$ & $14 \cdot 2$ & $16 \cdot 7-65 \cdot 2$ & $37 \cdot 2$ & 15.6 & $18 \cdot 5-82 \cdot 2$ \\
\hline & FFQ & $37 \cdot 1$ & $12 \cdot 2$ & $18 \cdot 1-63 \cdot 2$ & 31.8 & $11 \cdot 3$ & $15 \cdot 0-65 \cdot 4$ \\
\hline
\end{tabular}

* For details of procedures, see pp. 4-6.

generally similar between the two methods, with the notable exceptions of retinol, vitamin $\mathrm{B}_{12}$ and $\mathrm{Cu}$, where the questionnaire produced substantially narrower distributions.

Log-transformed correlation coefficients between the nutrient intake values based on the diet records and those based on the FFQ were lowest for $\mathrm{Zn}$ in women (0.34) and highest for protein, $\mathrm{Zn}$ and $\mathrm{Ca}$ in men $(\geqslant 0.75)$ (Table 4 ).

To evaluate the degree of misclassification arising when intakes were categorized using the simple FFQ, quintile cross-classification of subjects on the basis of both questionnaire scores and means from the five $2 \mathrm{~d}$ records was examined. Nutrient intakes were adjusted for total energy intake by simply dividing nutrient intakes by the energy intake derived from the same method (i.e. FFQ protein/FFQ energy). In this way men and women could be combined to give sufficient numbers for the quintile analysis, rather than using a less sensitive tertile analysis in men and women separately. Men and women had similar nutrient densities, but absolute intakes were generally higher in men as a result of their higher energy intakes. Using $\mathrm{Ca}$ as an example (Table 5), six of the eleven (55\%) subjects in the lowest quintile according to the diet records were also in the lowest quintile according to the questionnaire, and eight $(73 \%)$ were in the lowest two quintiles according to the questionnaire. Likewise, of those eleven subjects in the highest record quintile of $\mathrm{Ca}$ 
Table 4. Pearson correlation coefficients for comparison of food frequency questionnaire (FFQ) scores with the means of five $2 d$ diet records*, unadjusted for energy intake and excluding supplements for fifty-three elderly volunteers in Dunedin, New Zealand, 1989

\begin{tabular}{lcc}
\multicolumn{1}{c}{ Nutrient ${ }^{\dagger}$} & Men $(n$ 24) & Women $(n$ 29) \\
\hline Energy & 0.68 & 0.46 \\
Protein & 0.78 & 0.37 \\
Fat & 0.63 & 0.52 \\
Saturated fat & 0.74 & 0.66 \\
Polyunsaturated fat & 0.52 & 0.57 \\
Carbohydrate & 0.63 & 0.41 \\
Starch & 0.51 & 0.56 \\
Total sugars & 0.62 & 0.43 \\
Fibre & 0.67 & 0.59 \\
Cholesterol & 0.55 & 0.64 \\
Ca & 0.75 & 0.62 \\
Zn & 0.77 & 0.34 \\
Pyridoxine & 0.43 & 0.54 \\
Total folate & 0.58 & 0.49 \\
Ascorbic acid & 0.58 & 0.39 \\
Se & 0.61 & 0.40 \\
\hline
\end{tabular}

* For details of procedures, see pp. 4-6.

$\dagger$ Nutrient intakes transformed using $\log _{\mathrm{e}}$ to improve normality.

Table 5. Joint classification of energy-adjusted calcium intake assessed by the food frequency questionnaire ( $F F Q$ ) and five $2 d$ diet records* for fifty-three elderly volunteers in Dunedin, New Zealand, 1989

\begin{tabular}{|c|c|c|c|c|c|c|}
\hline \multirow[b]{2}{*}{ FFQ quintile } & \multicolumn{5}{|c|}{ Diet record quintile } & \multirow[b]{2}{*}{ Total } \\
\hline & 1 (low) & 2 & 3 & 4 & 5 (high) & \\
\hline 1 (low) & 6 & 2 & 3 & 0 & 0 & 11 \\
\hline 2 & 2 & 4 & 2 & 2 & 0 & 10 \\
\hline 3 & 2 & 3 & 3 & 3 & 0 & 11 \\
\hline 4 & 1 & 0 & 3 & 4 & 2 & 10 \\
\hline 5 (high) & 0 & 1 & 0 & 1 & 9 & 11 \\
\hline Total & 11 & 10 & 11 & 10 & 11 & 53 \\
\hline
\end{tabular}

* For details of procedures, see pp. 4-6.

density, nine $(82 \%)$ were in the highest FFQ quintile, and $100 \%$ were in the highest two questionnaire quintiles. Table 6 shows similar relationships for other nutrients. For twelve of the fourteen nutrients presented in Table 6 , at least $70 \%$ of the subjects when classified by the food records fell into the same quintile or into the within-one-quintile category when classified by the FFQ. Misclassification into extreme quintiles occurred for some subjects for fat, carbohydrate, polyunsaturated fat, sugars, and total folate.

\section{DISCUSSION}

In this study, the performance of a simple FFQ was evaluated by comparison with multiple days of diet recording. Every attempt was made to ensure the detail and accuracy of the records. Given that neither the reference method nor the questionnaire are perfect measures 
Table 6. Cross-classification of nutrient distribution quintiles from $10 \mathrm{~d}$ diet records and the food frequency questionnaire ( $F F Q$ ) (both intake scores adjusted for total energy intake) for fifty-three elderly volunteers in Dunedin, New Zealand, 1989*

\begin{tabular}{|c|c|c|c|c|c|c|c|}
\hline \multirow{2}{*}{$\begin{array}{l}\text { Diet record quintile ... } \\
\text { FFQ quintile ... } \\
\text { Nutrient }\end{array}$} & \multicolumn{3}{|c|}{ Lowest } & \multicolumn{3}{|c|}{ Highest } & \multirow{2}{*}{$\begin{array}{l}\text { Overall } \% \\
\text { correctly classified } \\
\text { within one quintile } \\
\text { of record quintile }\end{array}$} \\
\hline & $\begin{array}{c}\text { Lowest } \\
(\%)\end{array}$ & $\begin{array}{c}\text { Lowest } 2 \\
(\%)\end{array}$ & $\begin{array}{c}\text { Highest } \\
(\%)\end{array}$ & $\begin{array}{c}\text { Highest } \\
(\%)\end{array}$ & $\underset{(\%)}{\text { Highest } 2}$ & $\begin{array}{c}\text { Lowest } \\
(\%)\end{array}$ & \\
\hline Protein & 55 & 82 & 0 & 36 & 73 & 0 & 70 \\
\hline Fat & 27 & 45 & 18 & 36 & 55 & 9 & 62 \\
\hline Saturated fat & 73 & 91 & 0 & 27 & 64 & 0 & 77 \\
\hline PU fat & 55 & 91 & 0 & 45 & 64 & 9 & 75 \\
\hline Cholesterol & 55 & 73 & 0 & 55 & 91 & 0 & 72 \\
\hline Carbohydrate & 36 & 45 & 18 & 27 & 55 & 0 & 55 \\
\hline Sugars & 36 & 64 & 0 & 45 & 55 & 18 & 72 \\
\hline Fibre & 55 & 82 & 0 & 55 & 64 & 0 & 72 \\
\hline $\mathrm{Ca}$ & 55 & 73 & 0 & 82 & 100 & 0 & 83 \\
\hline $\mathrm{Zn}$ & 55 & 64 & 0 & 36 & 73 & 0 & 72 \\
\hline $\mathrm{Se}$ & 45 & 73 & 0 & 45 & 64 & 0 & 74 \\
\hline Pyridoxine & 36 & 82 & 0 & 55 & 73 & 0 & 70 \\
\hline Total folate & 45 & 73 & 9 & 36 & 55 & 9 & 72 \\
\hline Ascorbic acid & 55 & 82 & 0 & 45 & 82 & 0 & 77 \\
\hline
\end{tabular}

* For details of procedures, see pp. 4-6.

of dietary intake, it was important that the sources of error involved in the reference method were to a large extent different from those in the FFQ. Probably the main source of error in the reference method is the possibility of change in diet due to the measurement process itself, while the main sources of error in the questionnaire are the ability of subjects to describe a usual frequency of intake, restrictions imposed by a fixed list of foods, memory, interpretation of questions and the assumption of average serving sizes for most foods. Diet records are open-ended, do not depend on memory, they allow a more direct assessment of portion sizes, and errors in interpretation relate to the nutritionist coding the records rather than to the subject. Poor literacy skills and deliberate misinterpretation of eating patterns, however, will have the same effect on both methods of dietary assessment. A reference method that involved very similar errors to those in the questionnaire (e.g. the diet history interview) could lead to spuriously high estimates of validity.

In this study, comparisons of absolute nutrient intakes from the two methods are presented for a wide range of macronutrients and micronutrients. The similarity of the questionnaire-derived nutrient intake results for the study population to the results from a representative sample of over 700 elderly New Zealand people using the same FFQ (Horwath et al. 1992) provides some evidence of questionnaire reliability. It may also suggest that members of the general elderly population have a similar ability to complete such a questionnaire as the more highly-selected subjects participating in the present study.

The study population consisted only of healthy, independently-living Caucasian adults. As the study subjects were sufficiently cooperative to complete $10 \mathrm{~d}$ of detailed diet recording and were very different from the general population in terms of their interest in health, it is possible that the results reported here may overestimate the validity of the questionnaire when administered to a random population sample.

For most nutrients the questionnaire was highly successful in estimating mean intakes for the group. Over $80 \%$ of the FFQ nutrient intakes reported for men and two-thirds of those reported for women were within $10 \%$ of record values. The difference between the two 
methods was less than $25 \%$ for all but two of the twenty-six nutrients evaluated (i.e. total sugars and ascorbic acid for women only). The reasons why total sugars are overestimated but starch is underestimated by the FFQ relative to the diet record are unclear, given what appears to be similar coverage of food sources of both nutrients in the food list. Overall, at a group level, this questionnaire appears to perform better than other carefully-evaluated quantitative (Pietinen et al. 1988 a; Flegal \& Larkin, 1990), semi-quantitative (Willett et al. 1985 ) and qualitative instruments (Pietinen et al. 1988 b). These findings suggest that good agreement in group means can be achieved with the use of standard portion sizes for most food items on the FFQ.

The standard deviations found in this study for nutrient intakes derived from the five $2 \mathrm{~d}$ diet records were, with the exception of retinol, similar to those reported by Pietinen et al. (1988 a) for twelve $2 \mathrm{~d}$ diet records. However, a notable difference from several other studies comparing diet records and FFQ is that in the present study the standard deviations for nutrient intakes produced by the questionnaire were generally similar to those derived from the diet records. In other studies involving comparisons with between 16 and $28 \mathrm{~d}$ of diet recording, standard deviations were generally wider for the FFQ (Willett et al. 1985; Pietinen et al. 1988a; Flegal \& Larkin, 1990). In particular, Flegal \& Larkin (1990) report FFQ standard deviations that were 2-3 times wider than those derived from their $16 \mathrm{~d}$ diet records. The reduced variability of FFQ nutrient estimates in the present study is probably at least partly accounted for by the use of standard serving sizes for many of the food items. Questionnaires in the other studies had allowed for individual serving size estimates for all foods, thus producing greater variability in the nutrient intakes. The finding in the present study that retinol and vitamin $\mathrm{B}_{12}$ distributions from the $10 \mathrm{~d}$ records were markedly wider than those derived from the questionnaire may be explained in terms of the very high ratios of within- to between-subject variance for these nutrients, which means that longer than $10 \mathrm{~d}$ of diet recording is needed to estimate reliably the usual intakes for individuals (Marr \& Heady, 1986; Nelson et al. 1989). Thus, the questionnaire, in directly attempting to measure usual intake, produced a narrower range of intakes for these nutrients than the $10 \mathrm{~d}$ record; however, nutrient intakes averaged over a longer recording period would be expected to produce distributions and ranges more similar to those found here for the FFQ. Indeed, this is exactly what was found for retinol in the study of Pietinen et al. (1988a).

The range of correlations observed in the present study (most between 0.4 and 0.7 ) is comparable to that observed in other studies of FFQ and diet records (Epstein et al. 1970; Willett et al. 1985; Pietinen et al. 1988a,b).

The range of correlation coefficients for nutrient intakes (excluding supplements) between food records and FFQ in the present study was similar to that reported by Willett et al. (1985) for a range of macronutrients and micronutrients, excluding supplements, in a study comparing a FFQ and four 1-week diet records among 173 women aged 34-59 years. The unadjusted correlation coefficients reported by Pietinen et al. (1988b) for their comparison of a qualitative FFQ and twelve $2 \mathrm{~d}$ diet records in a group of Finnish men aged 55-69 years were also similar to those in the present study.

It is interesting to note that in terms of mean intakes and correlation coefficients, agreement between diet record and FFQ results appears to be much better in men than in women. This is contrary to what might be expected in an age cohort where shopping and food preparation have traditionally been performed by women and is generally assumed to produce a greater awareness of dietary intake in women.

The results for cross-classification of the nutrient intake distributions into quintiles were remarkably similar to those reported in other validation studies (Willett et al. 1985; Pietinen et al. 1988 b). Willett et al. (1985) reported that, on average, $48-49 \%$ of women in the lowest and highest quintiles based on food records were in the respective quintiles when 
assessed by the FFQ, and $74-77 \%$ were in the two lowest and two highest questionnaire quintiles. Similarly, the corresponding results of Pietinen et al. (1988b) for their qualitative FFQ were $40-45 \%$ and $70-75 \%$, respectively. On average, Pietinen et al. (1988b) found $72 \%$ of subjects when classified by the food records fell into the same or into the withinone-quintile category when classified by the short qualitative FFQ. The corresponding result for their long, quantitative food use questionnaire, however, was slightly better at $76 \%$ (Pietinen et al. 1988a). Misclassification into extreme quintiles was $3 \%$ for the FFQ of Willett et al. (1985), 4-5\% for the qualitative Finnish questionnaire (Pietinen et al. $1988 \mathrm{~b}$ ), and $4 \%$ for the quantitative Finnish food use questionnaire (Pietinen et al. 1988a).

The classification results, although consistent with previous literature, require more critical evaluation. Correct classification to within one quintile would be expected for $52 \%$ of subjects by chance alone. Thus, Table 6 suggests that this FFQ can be used to classify the intakes of most nutrients with the exception of carbohydrate. The degree of extreme misclassification was also greatest for carbohydrate and fat. Thus, individual results for these nutrients must be interpreted with extreme caution. From their study of a quantitative FFQ, Flegal \& Larkin (1990) suggest that errors in frequency estimation are the most important source of error in ranking individuals by levels of macronutrient intake.

In elderly populations, studies similar to the present one are rare. Jackson et al. (1990) compared fat, fibre and $\mathrm{Ca}$ intakes computed from a sixty-two item FFQ and a diet history interview in eighty elderly people. Mean FFQ intakes were only $77-79 \%$ of history values, correlation coefficients were only $0 \cdot 42-0.49$, and $49-58 \%$ of subjects were classified into the same tertiles of intake. The report, however, presented all findings for men and women combined, and the two methods being compared shared dependency on memory as a major source of error. Both factors would tend to create falsely-elevated correlations.

Although, as with previous investigations of a similar nature (Browe et al. 1966; Balogh et al. 1968; Epstein et al. 1970; Jain et al. 1982; Willett et al. 1987), the sample size in this study is relatively small, the findings provide further evidence that a short, simple selfadministered semi-quantitative FFQ can provide similar information to that obtained from a very demanding, time-consuming, expensive (in terms of coding and analysis) dietary assessment method.

In a group of healthy, independently-living Caucasian elderly people, the FFQ was able to produce group mean intakes for men and women that were within $10 \%$ of the record values for: energy, protein, carbohydrate, fat, saturated, polyunsaturated and monounsaturated fatty acids, cholesterol, alcohol, thiamin, riboflavin, nicotinic acid, pyridoxine, total folate, $\mathrm{Fe}, \mathrm{K}$ and $\mathrm{Zn}$, and also for fibre and retinol in men. The mean intakes which deviated most from the reference values were those for: starch, sugars, vitamin $\mathrm{B}_{12}$, ascorbic acid and $\mathrm{Ca}$. Ranking of individuals was achieved with reasonable accuracy relative to the record method for: protein, saturated and polyunsaturated fat, cholesterol, sugars, fibre, $\mathrm{Ca}, \mathrm{Zn}, \mathrm{Se}$, pyridoxine, total folate and ascorbic acid. Individuals' total fat and carbohydrate intakes could not be reliably classified. Thus, although a short, simple and largely qualitative instrument can be very useful among elderly populations, it may not provide group intakes and classification of individuals similar to $10 \mathrm{~d}$ of diet recording for all nutrients of interest, and the limitations must be remembered when interpreting results.

This questionnaire has proved sufficiently short and simple for a response rate of $85 \%$ to be achieved in an extensive multidisciplinary health survey involving elderly people in a small town near Dunedin ( $n$ 727). It must be stressed, however, that the validity of a FFQ is influenced by the adequacy of the food list and the ability of respondents to report a usual pattern of intake. In designing a new questionnaire it is vital that the food list be customized for the specific country or region, that the length and format is appropriate for the 
population of interest, and that the performance of the method be evaluated with a sample from this population.

This research would not have been possible without the excellent cooperation of the elderly Dunedin residents who participated so willingly in this study. Grateful thanks to Ross Marshall (Assistant Lecturer, Department of Human Nutrition) for writing the FFQ analysis program and for assistance with computing.

\section{REFERENCES}

Baghurst, K. I. \& Record, S. J. (1983). Intake and sources, in selected Australian subpopulations, of dietary constituents implicated in the aetiology of chronic diseases. Journal of Food and Nutrition 40, 1-15.

Baghurst, K. I. \& Record, S. J. (1984). A computerised dietary analysis system for use with diet diaries or food frequency questionnaires. Community Health Studies 8, 11-18.

Baghurst, K. I. \& Record, S. J. (1987). The vitamin and mineral intake of a free-living young elderly Australian population in relation to total diet and supplementation practices. Human Nutrition Applied Nutrition 41A, 327-337.

Balogh, M., Medalie, J. H., Smith, H. \& Groen, J. J. (1968). The development of a dietary questionnaire for an ischaemic heart disease survey. Israeli Journal of Medical Science 4, 195-203.

Birkbeck, J. A. (1983). New Zealanders and their diet. A report to the National Heart Foundation of New Zealand on the National Diet Survey 1977. 2nd ed. Dunedin: University of Otago.

Block, G. (1982). A review of validations of dietary assessment methods. American Journal of Epidemiology 115 , $492-505$.

Block, G., Hartman, A. M., Dresser, C. M., Carroll, M. D., Gannon, J. \& Gardner, L. (1986). A data based approach to diet questionnaire design and testing. American Journal of Epidemiology 124, 453-469.

Browe, J. H., Gofstein, R. M., Morlley, D. M.\& McCarthy, M. C. (1966). Diet and heart disease study in the cardiovascular health centre. Journal of the American Dietetic Association 48, 95-108.

Campbell, V. A. \& Dodds, M. L. (1967). Collecting dietary information from groups of older people. Journal of the American Dietetic Association 51, 29-35.

Epstein, L. M., Rfeshef, A., Abramson, J. H. \& Bialik, O. (1970). Validity of a short dietary questionnaire. Israel Journal of Medical Sciences 6, 589-596.

Flegal, K. M. \& Larkin, F. A. (1990). Partitioning macronutrient intake estimates from a food frequency questionnaire. American Journal of Epidemiology 131, 1046-1058.

Guthrie, H. A. (1984). Selection and quantification of typical food portions by young adults. Journal of the American Dietetic Association 84, 1440-1444.

Horwath, C. C. (1989). Dietary survey of a large random sample of elderly people: energy and nutrient intakes. Nutrition Research 9, 479-492.

Horwath, C. C., Campbell, A. J. \& Busby, W. (1992). Dietary survey of an elderly New Zealand population. Nutrition Research 12, 441-453.

Horwath, C. C. \& Worsley, A. (1990). Assessment of the validity of a food frequency questionnaire as a measure of food use by comparison with direct observation of domestic food stores. American Journal of Epidemiology 131, $1059-1067$.

Jackson, N., Little, J. \& Wilson, A. D. (1990). Comparison of diet history interview and self completed questionnaire in assessment of diet in an elderly population. Journal of Epidemiology and Community Health 44, $162-169$.

Jain, M. G., Harrison, L., Howe, G. R. \& Miller, A. B. (1982). Evaluation of a self-administered dietary questionnaire for use in a cohort study. American Journal of Clinical Nutrition 36, 931-935.

Kelsey, J. L., O'Brien, L. A., Grisso, J. A. \& Hoffman, S. (1989). Issues in carrying out epidemiologic research in the elderly. American Journal of Epidemiology 130, 857-867.

Maclure, M. \& Willett, W. C. (1987). Misinterpretation and misuse of the kappa statistic. American Journal of Epidemiology 126, I61-169.

Marr, J. W. \& Heady, J. A. (1986). Within and between person variation in dietary surveys: number of days needed to classify individuals. Human Nutrition Applied Nutrition 40A, 347-364.

Milligan, G. C., Webster, D. W. \& Burlingame, B. A. (1991). The New Zealand Food Composition Tables. Wellington: Department of Scientific and Industrial Research.

Nelson, M., Black, A. E., Morris, J. A. \& Cole, T. J. (1989). Between- and within-subject variation in nutrient intake from infancy to old age: estimating the number of days required to rank dietary intakes with desired precision. American Journal of Clinical Nutrition 50, 155-167.

Nelson, M., Hague, G. F., Cooper, C. \& Bunker, V. W. (1988). Calcium intake in the elderly: validation of a dietary questionnaire. Journal of Human Nutrition and Dietetics 1, 115-127.

Pietinen, P., Hartman, A. M., Haapa, E., Rasanen, L., Haapakoski, J., Palmgren, J., Albanes, D., Virtamo, J. \& 
Huttunen, J. K. (1988). Reproducibility and validity of dietary assessment instruments. I. A self-administered food use questionnaire with a portion size picture booklet. American Journal of Epidemiology 128, 655-666.

Pietinen, P., Hartman, A. M., Haarpa, E., Rasanen, L., Haapakoski, J., Palmgren, J., Albanes, D., Virtamo, J. \& Huttunen, J. K. (1988). Reproducibility and validity of dietary assessment instruments. 2. A qualitative food frequency questionnaire. American Journal of Epidemiology 128, 667-676.

Rapp, S. R., Dubbert, P. M., Burkett, P. A. \& Buttross, Y. (1986). Food portion size estimation by men with type II diabetes. Journal of the American Dietetic Association 86, 249-251.

Samet, J. M., Humble, C. G. \& Skipper, B. E. (1984). Alternatives in the collection and analysis of food frequency interview data. American Journal of Epidemiology 120, 572-581.

Trulson, M. F. \& McCann, M. B. (1959). Comparison of dietary survey methods. Journal of the American Dietetic Association 35, 672 .

Willett, W. C., Reynolds, R. D., Cottrell-Hoehner, S., Sampson, L. \& Browne, M. L. (1987). Validation of a semiquantitative food frequency questionnaire: comparison with a 1-year diet record. Journal of the American Dietetic Association 87, 43-47.

Willett, W. C., Sampson, L., Stampfer, M. J., Rosner, B., Bain, C., Witschi, J., Hennekens, C. H. \& Speizer, F. E. (1985). Reproducibility and validity of a semi-quantitative food frequency questionnaire. American Journal of Epidemiology 122, 51-65.

Wilson, N. C., Russell, D. G., Paulin, J. M., Hopkins, W., Horwath, C. C., Mann, J., Nye, T., Parnell, W., Spears, G., Wilson, B., Worsley, T., Cushman, G., Laidler, A. \& Birkbeck, J. (1990). Life in New Zealand Summary Report. Dunedin, New Zealand: University of Otago. 